\title{
Efficiency of conventional extraction technique compared to rapid-solid liquid dynamic extraction (RSLDE) in the preparation of bitter liquors and elixirs
}

\author{
Daniele Naviglio ${ }^{1}$, Lydia Ferrara ${ }^{2 *}$, Andrea Formato ${ }^{3}$, Monica Gallo ${ }^{4}$ \\ ${ }^{I}$ Department of Chemical Sciences, University of Naples Federico II, via Cintia 4, 80126 Naples, Italy \\ ${ }^{2}$ Department of Pharmacy, University of Naples, Federico II, Via Domenico Montesano 49, 80131 Naples, Italy \\ ${ }^{3}$ Department of Agriculture, University of Naples Federico II, via Università, 100, 80055 Portici (Naples), Italy \\ ${ }^{4}$ Department of Molecular Medicine and Medical Biotechnology, University of Naples Federico II, via Pansini \\ 5, 80131 Naples, Italy
}

\begin{abstract}
Bitter liquors and elixirs are usually produced following traditional recipes, in most cases considered secret, that adopts different extraction processes and/or way of preparation. The ethanol as elective extraction solvent allows to obtain in the liquid phase most of the active compounds from different parts of the plants e.g. roots, bark, flowers, etc and the maceration is commonly used as extraction process. In this paper the traditional maceration procedure was compared to an innovative technology of rapid solid-liquid dynamic extraction (RSLDE), using the Naviglio Extractor. to obtain alcoholic extract of herbal mixtures.Three different mixtures of various parts of plants were extracted with both methods and results compared. The dry residue was considered as the main parameters to assess the quantity of the active compounds present in the extracts. The obtained data suggested that an high dry residue amount in the extract was correlated to an high concentration of active ingredients. Organoleptic tests performed on bitter liquors obtained from different extracts has been used to determine the optimum extraction time for the two different methods used. The results of this test showed that the bitters produced with RLSDE were more appreciated than bitter prepared by maceration.
\end{abstract}

KEYWORDS - bitter liquors; elixir; maceration; RSLDE; Naviglio Extractor; kinetics.

\section{INTRODUCTION}

The extracts obtained from medicinal herbs are made from a pool of substances of intense bitter taste, and are generally used as eupeptic and gastric secretion stimulant compounds[1].The mechanism of action involves awareness of mouth taste receptors associated with a nervous stimulus that activate as a reflex the gastric secretion [2]. Since the Middle Ages, monastic orders like the Carthusians, Franciscans, Benedictines, and Cistercians, started to study the flora in the proximity of the monasteries and their experiments allowed to select herbs with different properties that, once dried, were macerated in alcohol and, sometimes, even distilled. The herbs used for extracts and bitter liquors preparation include sage, thyme, rue, angelica, peppermint, gentian and artemisia $^{2}$. To produce a liqueur, the aromatic part of the plant or flowers, were placed in an ethanol infusion to extract the essential oils, aromas, colours, and flavours. The traditional maceration process used to extract the aromatic and active substances lasted a variable period of time, ranging from 10 to 40 days, with moderate stirring. The obtained mixture was then filtered and mixed with a concentrated syrup of sugar and with water to lower the alcohol content and to make the mixture more palatable[2,3]

Bitter beverages can range from the ones prepared using parts, e.g. leaves, of individual plants (Gentian, Quassia), to the alkaloid drinks (china, nux vomica), the aromatic drinks (angelica, bitter orange), the mucilaginous drinks (Colombo, Icelandic lichen), and the salted drinks (milk thistle, chicory). Herbs are also included in the bitter extracts preparation. Their original pharmaceutical use stimulated also the making of bitter extracts to be used to prepare liquors and elixirs with beneficial effects on human [3-5]

The complexity of the vegetal matrix to extract, often made from a mixture of different parts from several plants causes difficulty to reproduce the same extract due to the natural variability of the constituents of each plant from one year to another. Moreover some negative aspects of the maceration process itself, like the slow diffusion of substances from the inside of the supersaturated solid matrix that generates a compound near the surface of the solid, need to be considered. This last aspect can be associated to a probability increase of chemical changes of the extracted compounds due to the procedure itself[6-8]. In addition, since plants are water-rich matrices $(50 \%$ bark, $90 \%$ leaf, flavedo $70 \%$, w/w) the micro water rich environment found in the proximity of the inside of the plant is different from the environment of the solution made in the conventional extraction by maceration processes[4]. 
In this paper, it was evaluated the efficiency of the extraction by an innovative technology of rapid solid-liquid dynamic extraction (RSLDE), using the Naviglio Extractor, compared to the conventional technique of maceration, for the production of bitters and elixirs. In the literature, different applications of this technology of solid-liquid extraction were. Three different mixtures of plants used for the production of bitter extract were evaluated. The kinetic curves of alcohol extraction obtained using the RSLDE were compared with those obtained with the maceration. The dry residue obtained from the extracts was considered as relevant indicator for measuring the levels of active principles extracted and, consequently, the total concentration of the extract. In addition, the spectrophotometric analyzes allowed to identify the main substances present in the extract showing a maximum at wavelength of $340 \mathrm{~nm}$ responsible for the presence of tannins in the bitter liquors and elixirs, based on the data known from the literature on the composition of three different herbal mixtures used

\subsection{Instruments}

\section{MATERIALS AND METHODS}

Closable Infuser (glass vessel $250 \mathrm{~mL}$ volume). Naviglio Extractor mod. 500 cc (Atlas Filtri Engineering, Limena (Padua, Italy), stove EU-77L (Thermoelectron Corporation, Waltham, MA, USA), analytical balance (Mettler Toledo, Switzerland), UV-VIS spectrophotometer, mod. UV-1601 (Shimadzu, Tokyo, Japan), equipped with quartz cuvettes with $1.00 \mathrm{~cm}$ optical path (Shimadzu, Tokyo, Japan

\subsection{Herbal samples}

Three different herbal mixture have been used. The first mixture (swedish herbs) was constituted by $10 \mathrm{~g}$ of Aloe, $5 \mathrm{~g}$ of Myrrh, $0.2 \mathrm{~g}$ of Saffron, $10 \mathrm{~g}$ of Cassia leaves, $10 \mathrm{~g}$ of Camphor, $10 \mathrm{~g}$ of Rhubarb root, $10 \mathrm{~g}$ of Curcuma root, $10 \mathrm{~g}$ of Manna, $10 \mathrm{~g}$ Venetian Treacle, $5 \mathrm{~g}$ of Carlina root and $10 \mathrm{~g}$ of Angelica root. The second mixture (mixture of vanilla China) was constituted by $85 \mathrm{~g}$ of China herbs mixture, $8 \mathrm{~g}$ of Bitter Orange, $7 \mathrm{~g}$ of Vanilla pod. The third mixture (Polcaro bitter mixture) contained $20 \mathrm{~g}$ of Angelica, $10 \mathrm{~g}$ of Calamus, $10 \mathrm{~g}$ of Licorice, 20g of Fennel, $10 \mathrm{~g}$ of Melissa, 20g of Gentian and $10 \mathrm{~g}$ of Centaurea. All the herbs and vegetal components were purchased from the local market in Naples (Italy). The Polcaro mixture was obtained from the producer (Polcaro Phytopreparations, Roccarainola, Naples, Italy). All experiments were done in triplicate and results averaged.

\subsection{Preparation of samples by maceration}

Portions constituted by 30 grams of each mixture were accurately weighted and transferred in separate vessels (infusers). The vessels were added with $550 \mathrm{~mL}$ of ethyl alcohol $40 \%(\mathrm{v} / \mathrm{v})$ and were kept at room temperature in the dark to simulate the traditional procedure. The vessels were stirred every day and stored for two, three, and four weeks. The alcoholic mixtures obtained (elixir) were transferred in a clean vessel and stored.

\subsection{Conventional procedure by maceration for bitter liquors preparation}

Each mixture of herbs was extracted by maceration in ethyl alcohol $40 \%(\mathrm{v} / \mathrm{v})$ for 14 days, and stirred occasionally. The alcoholic extract was recovered by paper filtering. 5 grams of sugar were added every $100 \mathrm{~mL}$ of the ethyl alcohol extract, and the mixture stirred until the sugar was completely dissolved.

\subsection{Rapid solid-liquid dynamic extraction (RSLDE)for bitter liquors preparation}

Thirty grams $30 \mathrm{~g}$ of each mixture of herbs were introduced using a sterile microporous filtering bag (pores diameter $100 \mu$ )in the Naviglio Extractor (Fig. 1) and added with $550 \mathrm{~mL}$ of ethyl alcohol $40 \%$ (v/v). Details of the principle of the dynamic solid liquid extraction are given elsewhere. [9] The extraction generated a pressure gradient on a solid matrix in the appropriate solvent. An overall representation of its functioning and of the steps involved is shown in Fig. 2. The Scheme 1 shows the embebbed processes in the Naviglio Extractor and reports also the operative working condition parameters. The extractor was set to perform 198 extraction cycles of 4 minutes each ( 2 minutes in static phase and 2 minutes in dynamic phase) for a total of 12 hours extraction time. Hydroalcholic solution was removed at the end of extractive process and the gently squeezing of the bag containing the herbs allowed the recovery of totality of liquid. The alcoholic mixture obtained (elixir) was transferred in a clean vessel and stored. To prepare the bitter liquor, $5 \mathrm{~g}$ of sugar were added in $100 \mathrm{~mL}$ of ethyl alcohol extract and the mixture stirred until the sugar was completely dissolved.

\subsection{Determination of dry alcoholic extract at $105^{\circ} \mathrm{C}$}

$10 \mathrm{~mL}$ of the alcoholic extract previously filtered on paper were transferred to a calibrated porcelain melting pot. The liquid was allowed to dry initially at a temperature of $50{ }^{\circ} \mathrm{C}$ and, after the volume reduction, at an oven temperature of $105{ }^{\circ} \mathrm{C}$. The melting pot was allowed to equilibrate at room temperature and then the weight has been accurately determined using an analytical balance. Measurements were made in triplicate and results expressed as mean \pm standard deviation $(\mathrm{M} \pm \mathrm{SD})$. 


\subsection{Absorbance spectrum measure of the herbs alcoholic extracts}

The spectrophotometer was calibrated in the range of wavelength $200-400 \mathrm{~nm}$ using a $40 \%$ (v/v) ethyl alcohol solution. The absorbance spectrum of alcoholic extract opportunely diluted was measured and recorded. All measurements were made in triplicate and results expressed as mean \pm standard deviation $(\mathrm{M} \pm \mathrm{SD})$.

\subsection{Taste test}

A brief taste test was employed at the end of two extractions. Ten people regular consumers of bitter liquors, 7 males and 3 females, aged between twenty and thirty years, were selected to perform the organoleptic assay and liquor comparison. Participants also answered questions regarding the taste of liquors. The test was limited to an assessment of preference among the bitter liquors produced by the traditional method and by RSLDE.

\subsection{Extraction kinetics using the maceration method}

\section{RESULTS AND DISCUSSION}

Maceration at room temperature in ethyl alcohol is a very old technique for extracting active ingredients from medicinal plants. This extraction process is based as on the diffusion of molecules from the vegetal matrix into the outside liquid phase. The affinity polarity has a key role; molecules tend to pass from the solid matrix to the liquid phase and dissolve in the extraction solvent as a result of an osmosis process. Stirring in order to lower concentration in the immediate neighbourhood of the solid matrix, usually allows to obtain amore rapid extraction gradient, while temperature raise allows the entropy to grow up and then accelerates the extractive process.

Fig. 3 shows the extraction kinetics of the three bitter mixtures subjected to maceration process. Experimental results are shown in Table 1, where it is possible to observe the extraction process performance is similar. At the same time, it is also possible to note that the extraction process is slow, and the system reached equilibrium after 10 days. This is represented in the Fig. 3 by the saturation value, obtained for all mixtures after about 240 hours of extraction, about ten days. The function that best interpolates the experimental points is of the type $C(t)=S * e^{-(k / t)}$, where $C(t)$ represents the concentration at time $t, S$ is the saturation value, the maximum value reached by the concentration and that remains constant until the value of $t=$ infinity. The value of $k$, the kinetic constant, represents the speed with which the system reaches equilibrium, and it is expressed in units of time (hours).

This function indicates that the system, kept at room temperature and pressure with stirring, reaches saturation after 240 hours, and, therefore the initial extractive phase lasts for a long time.

In previous papers $[10,11]$ it has been highlighted that during maceration of lemon peel in ethyl alcohol, essential oils including limonene, beta-pinene and gamma-terpinene were extracted with a kinetic faster than the others minor components, e.g. sabinene, alpha-pinene and geranial, less important for the complete beverage flavour. This was related both to different solubility of compounds in ethyl alcohol and to the different distribution of these compounds in the essential oil of lemon. Micali et al., have shown that in case of leaves maceration of hypericum (Hypericum perforatum) the twenty-one maceration days indicated by the Official Pharmacopoeia were completely ineffective to extract the active ingredient hypericin[11].

\subsection{Extraction kinetics using the RSLDE}

Fig. 4 shows the kinetic curves obtained using the RSLDE. The numerical data are shown in Table 2. In it can be observed that the experimental data are well interpolated, in this case too, by the function like $C(t)=S * e^{-(k / t)}$. The trend of rapid solid-liquid dynamic extraction kinetic was the same as that of maceration. The only main difference was the value of the rate constant $\mathrm{k}$. In this case, the initial part of the extraction was very fast and the system reached equilibrium in about 12 hours indicating that the RSLDE was at least twenty times faster. In fact, the value of the rate constant $\mathrm{k}$ in the case of maceration was about 20h, while in the solid-liquid dynamic fast extraction case was of about $1 \mathrm{~h}$. This extraction acceleration was possible because the Naviglio Extractor generated a negative pressure gradient between inside and outside of the solid matrix and substances contained in the solid are extracted by means of a "suction" effect. This was the driving force behind the extraction, and due to this gradient, the solid-liquid extraction had an active mechanism forcing the molecules to move from inside the solid matrix to the outside liquid phase[5,6].

The values of the dry weight obtained by RSLDE is slightly lower, about $10 \%$, in all cases compared to the value obtained with the maceration technique. This difference could be explained considering that a prolonged contact between extracting liquid and solid phase produces colloidal particles that were dispersed in system and increase value of dry weight; these colloidal particles comes down in time and are responsible of a mould taste. 


\subsection{RSLDE as forecast of maceration kinetic}

Previous data indicate that the lemon liqueur also called "limoncello" was obtained in only two hours with fast extraction using the Naviglio Extractor instead of the seven days of maceration of peels in ethyl alcohol as suggested by the traditional procedure[9].. Similarly, for berries liqueur production by alcoholic extraction in ethyl alcohol, only 36 hours were needed to obtain a liquor using the RSLDE that had no appreciable differences from the one produced by macerating the berries in ethyl alcohol for twenty days, about 480 hours.[12]. Applying the model of bitter liquors to this last case, the minimum time of maceration could be predicted starting from ten hours of RSLDE and allowed to obtain saturation after 200 hours (10 hours x 20), e.g. about eight days, more lengthy compared to conventional maceration

\subsection{Ethyl alcohol recovery after extraction process}

Comparing the extracts obtained from the Vanilla China mixture after 2, 4 and 12 hours using the RSLDE with the extract obtained after two weeks of maceration mixture of the same plants, keeping unchanged the solid / liquid ratio that was used as a reference for the 'intensity of the color, it was possible to observe that the extract obtained with RSLDE after only 12 hours had the same intensity of color of the extract obtained in the traditional way.. This visual comparison was in agreement with the determination of dry residue made previously and with the values of the kinetic constant of the extraction process. It was also important to outline the marked loss of ethyl alcohol in the extraction process by maceration; in this case, in fact, the recovery was only about $80 \%$, the remaining twenty percent was lost in solid matrix and represented a loss in production of bitter liquors. In the RSLDE, the loss of ethyl alcohol was negligible, and this was an another point in favour of this innovative solid-liquid extraction technique. Moreover, the minimum time of contact between solid and liquid prevented the release of unwanted substances in the extract. In fact, a prolonged contact of ethyl alcohol with herbs during maceration promoted disintegration of the solid matrix and the releases of unwanted substances (colloidal particles). In addition, during prolonged time of extraction (i.e. after 20 days), transformation of substances extracted occurred and the system underwent a phase of "aging". This phenomenon caused a slight increase of dry weight observed in maceration for all cases considered with respect to fast high pressure extraction. In the long run, the extract started to get rich in colloidal substances which arised partly from solid matrix and partly derived from polymerization reactions occurring between the compounds present in the extract solution[5,6].

\subsection{Rapid solid-liquid dynamic performs aspecific extractions}

Traditional extraction techniques such as maceration, percolation, Soxhlet extraction, etc., are based on diffusion and osmosis, and allow the extraction of the substances that can dissolve in the extracting liquid. In the rapid solid-liquid dynamic extraction with the RSLDE, the driving force of the extraction was the pressure difference between inside and outside of the solid matrix. Substances that were not chemically bound to the solid matrix were "sucked" due to the deep depression generated by the device and then by the strong movement of the liquid phase. This way, the molecules not soluble in the extraction liquid were borne out in the heterogeneous phase (see Fig. 2). Some applications reported in the literature as extraction of lycopene from tomato peel with water and extraction of essential oils with water[13], showed that it was possible to extract in water, a polar solvent, also hydrophobic substances.

Other examples of its applications were the extraction of active ingredients from Malva silvestris[14], extraction of contaminated soil[15], and extraction of main components of hop added in the beer production process[16].

\subsection{Evaluation of organoleptic assay results and spectrophotometric measure}

Organoleptic assay results indicated that bitter liquors prepared from extracts, obtained according to traditional and innovative procedures, were equivalent to taste and to flavor. Six out of ten tasters showed notes of "aged" and/or "rot" in bitters produced by traditional procedure.

Spectrophotometric analysis of the extracts showed an intense absorption peak in the region between 230 and 280 $\mathrm{nm}$ responsible for polyphenols and tannins. Figure 5 shows a spectrum obtained at the beginning (A) and at the end (B) of the RSLDE. This measurements allowed to give another result of the increasing of efficiency of extraction against time. The complete identification of the compounds in the extracts was not the purpose of the present work considering the non specificity of the extraction procedures used.

\subsection{Taste test}

After sample preparation, the students have carried out a taste test and were asked to give their opinion on: Appearance, Taste/Flavor, Texture rating, Aroma/Smell rating. Overall acceptability of the products obtained by filling out an evaluation form containing 5 degrees of judgment. (Table 3). The subjects were advised to use water to rinse their mouths between samples. The samples were presented coded by three-digit numbers and in random order. They were evaluated at room temperature following the indications as reported in literature[17]. The results of this test showed that the bitters produced with RLSDE were more appreciated than bitter prepared by maceration. This conclusion supports experimental data that showed a better quality for the extracts obtained by the innovative technique of RSLDE. 
IV. FIGURES AND TABLES

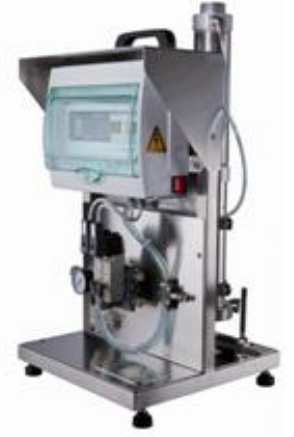

(A)

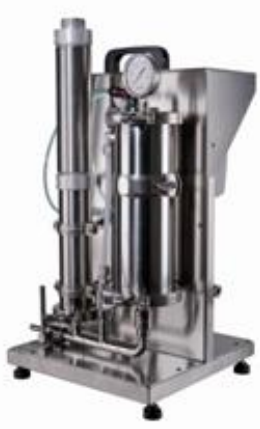

(B)

Figure 1. Naviglio Extractor mod. $500 \mathrm{cc}$. Front (A) and rear (B) views.

(A)

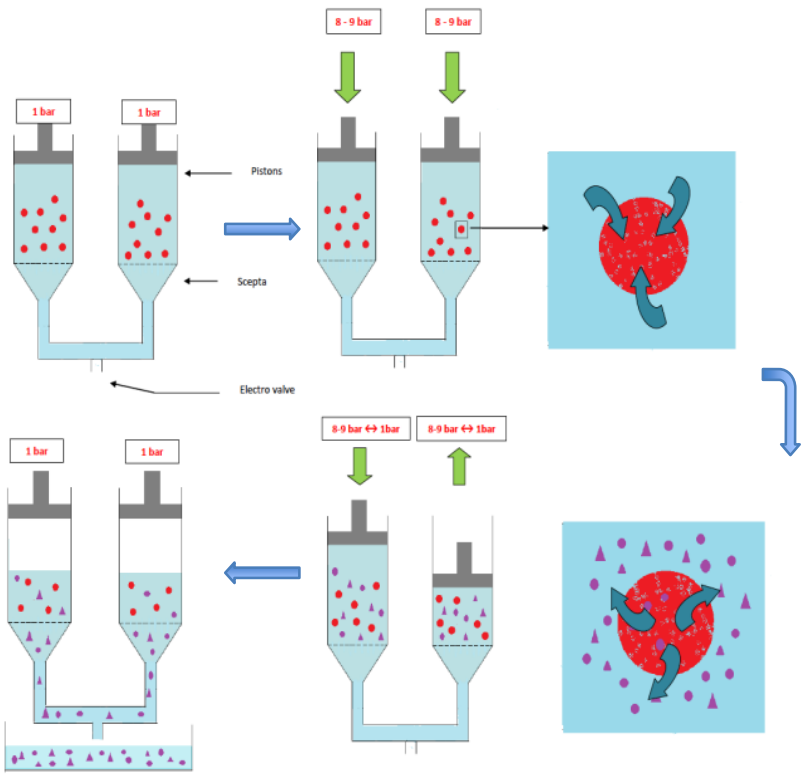

(B)

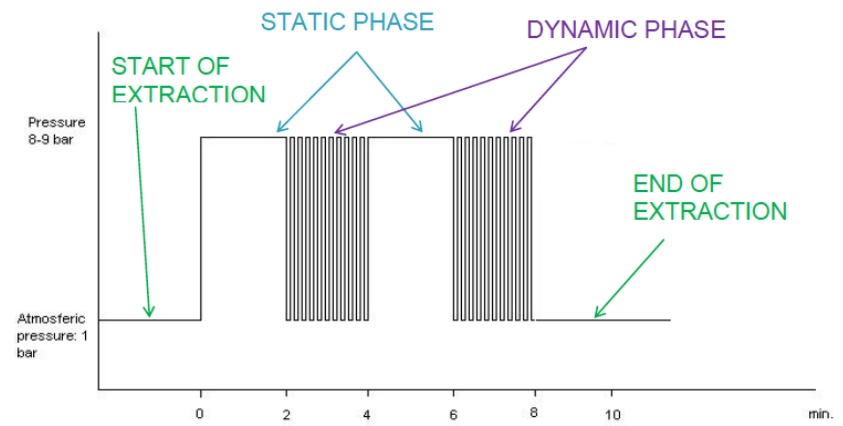


Figure 2. (A) Starting left to right: extractive chambers with matrix (red circles) and solvent (in blue) at atmospheric pressure; static phase, water seepage into the matrix (blue arrows); dynamic phase and suction effect generated from pressure gradient, release due to the pressure gradient from the inside of the matrix to the outside; end of extraction and release of extracted substances.

(B) General aspect of a Pressure vs Time plot during the extraction

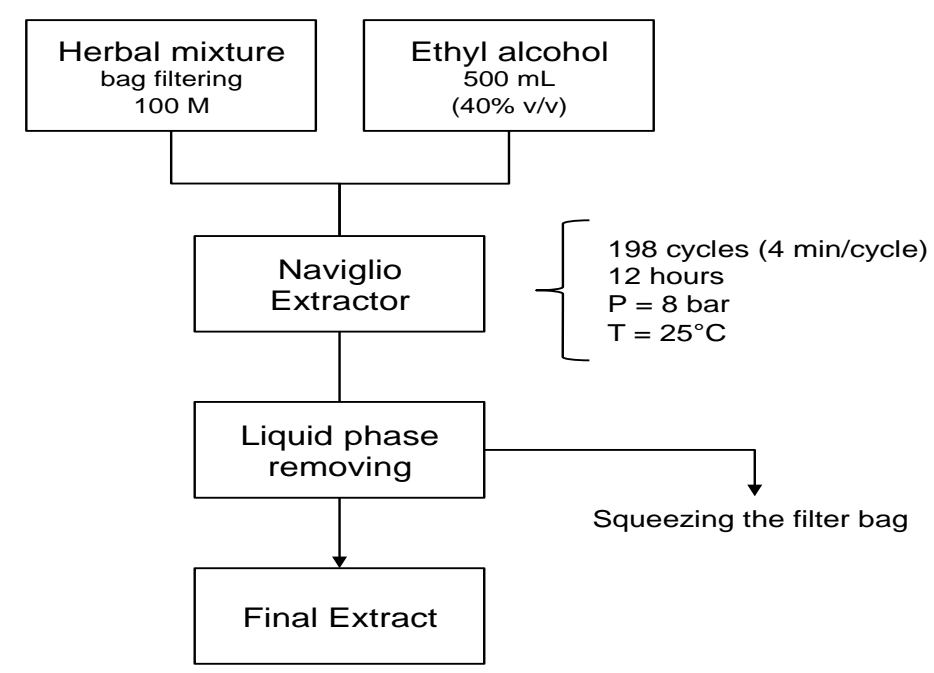

Scheme 1. Flow diagram to show the processes imbedded in the RSLDE. Operative working condition parameters are reported.
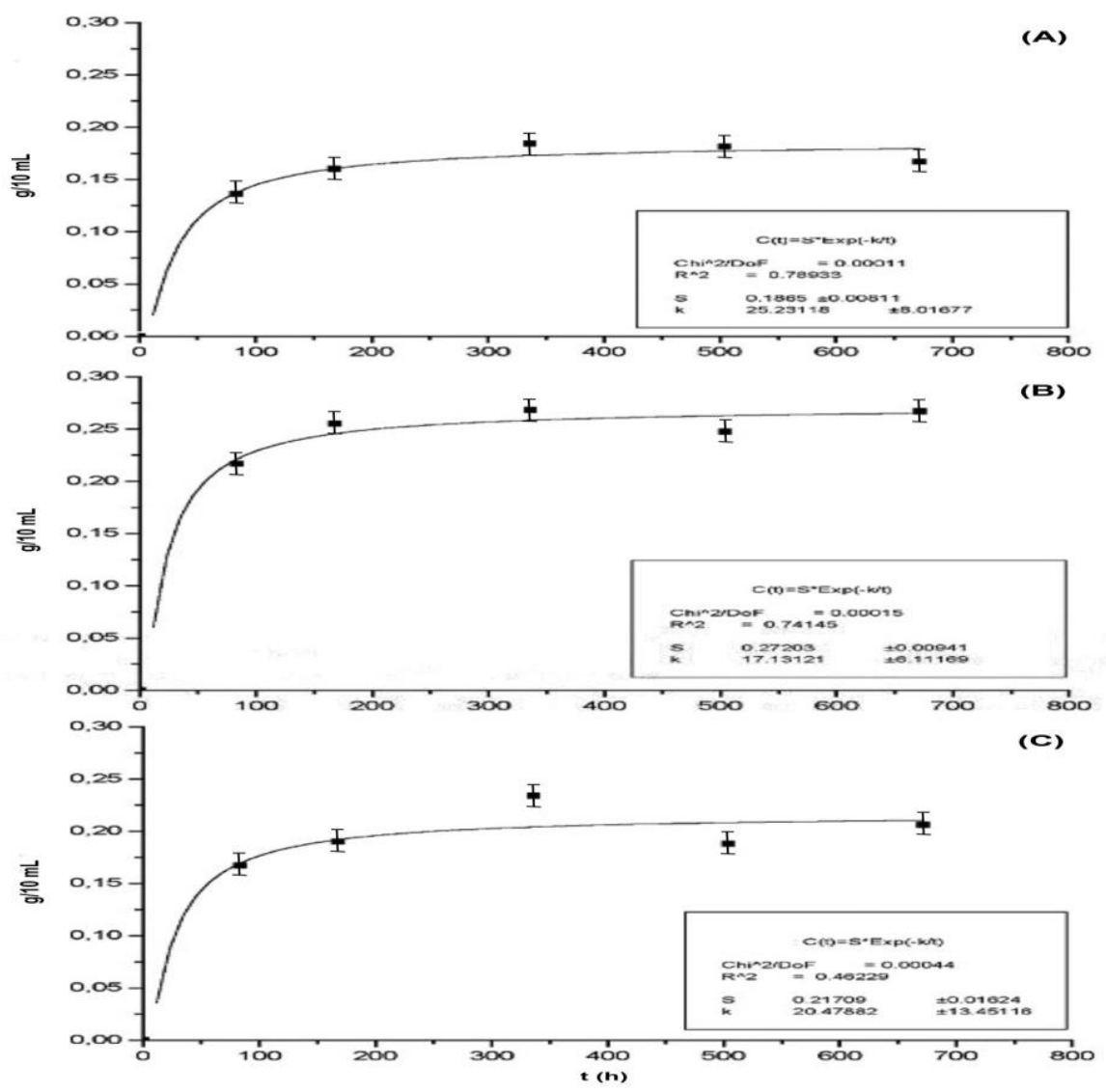
Figure 3. Extraction kinetic of the Polcaro bitter mixture (A), Swedish herbs bitter mixture (B), and Vanilla Chinabitter mixture(C), after ethyl alcohol maceration. Plots report the dry residue amount ( $\mathrm{g}$ in $10 \mathrm{~mL}) \mathrm{vs}$ time $(\mathrm{h})$.

Table 1. Experimental data obtained by extraction of the 3 different plants herbal mixtures using maceration and relative values of saturation $(S)$ and kinetic constant $(k)$ obtained by interpolation of the function $C(t)=S^{*} e^{-k} / t$.

\begin{tabular}{|l|l|l|l|}
\hline Time (hours) & Swedish herbs Mixture C $(\mathrm{t})$ & Vanilla China Mixture $\mathrm{C}(\mathrm{t})$ & Polcaro Mixture C $(\mathrm{t})$ \\
\hline 0 & 0 & 0 & 0 \\
\hline 84 & 0.217 & 0.167 & 0.136 \\
\hline 168 & 0.255 & 0.190 & 0.160 \\
\hline 336 & 0.268 & 0.234 & 0.184 \\
\hline 504 & 0.247 & 0.188 & 0.181 \\
\hline 672 & 0.267 & 0.206 & 0.167 \\
\hline $\mathrm{S}$ (saturation) & $0.272 \pm 0.009$ & $0.217 \pm 0.016$ & $0.186 \pm 0.008$ \\
\hline k (kinetic constant) & $17.131 \pm 6.111$ & $20.479 \pm 7.451$ & $25.231 \pm 8.017$ \\
\hline
\end{tabular}

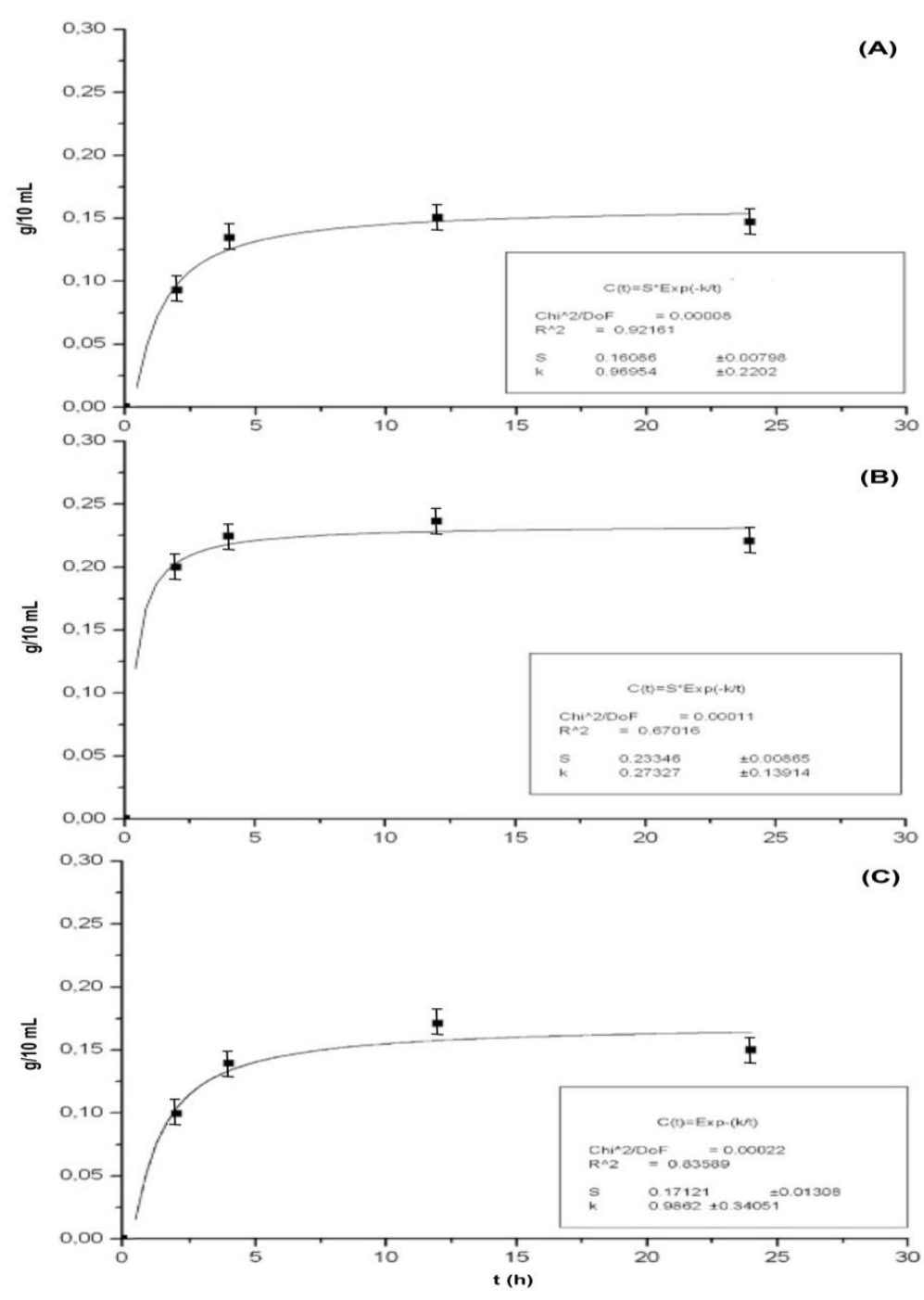

Figure 4. Extraction kinetic of the Polcaro bitter mixture (A), Swedis herbs bitter mixture (B), and Vanilla China bitter mixture (C), after extraction with the RSLDE. Plots report the dry residue amount (g/10 mL) vs time (h). 
Table 2.Experimental data obtained by extraction of the 3 different plants herbal mixtures with the RSLDE and relative values of saturation $(S)$ and kinetic constant $(k)$ obtained by interpolation of the function $C(t)=S^{*} e^{-k / t}$.

\begin{tabular}{|l|l|l|l|}
\hline Time (hours) & Swedish herbs Mixture C $(\mathrm{t})$ & Vanilla China Mixture C $(\mathrm{t})$ & Polcaro Mixture C(t) \\
\hline 0 & 0 & 0 & 0 \\
\hline 2 & 0.200 & 0.099 & 0.093 \\
\hline 4 & 0.224 & 0.139 & 0.135 \\
\hline 12 & 0.236 & 0.171 & 0.151 \\
\hline 24 & 0.220 & 0.150 & 0.148 \\
\hline S (saturation) & $0.233 \pm 0.009$ & $0.171 \pm 0.013$ & $0.161 \pm 0.008$ \\
\hline $\mathrm{k}($ kinetic constant) & $0.273 \pm 0.139$ & $0.986 \pm 0.340$ & $0.969 \pm 0.220$ \\
\hline
\end{tabular}
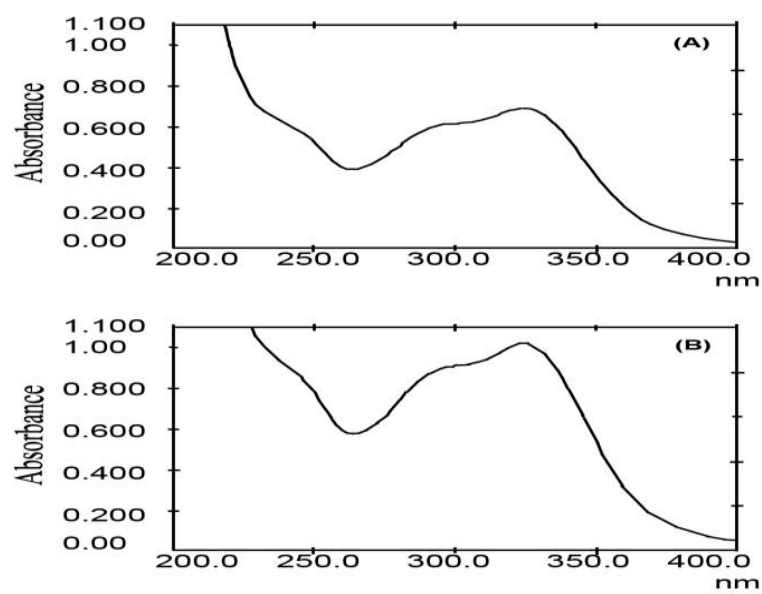

Figure 5. UV-VIS spectrogram obtained at the beginning (A) $(\mathrm{t}=0 \mathrm{~h})$, and at the end (B) of the extraction process $(\mathrm{t}=12 \mathrm{~h})$ with the RSLDE. Wavelengths scan between 200 and $400 \mathrm{~nm}$.

Table 3. Sensory evaluation form compiled by panelists for the taste test.

\begin{tabular}{|c|c|c|c|c|c|}
\hline \multicolumn{6}{|c|}{ Sensory Evaluation Form } \\
\hline \multicolumn{3}{|l|}{ Recipe Name: } & \multicolumn{3}{|l|}{ Category: } \\
\hline \multicolumn{6}{|c|}{$\begin{array}{l}\text { Directions: Circle one rating in the yellow boxes for each of the following: Appearance, Taste/Flavor, Texture/Consistency, } \\
\text { Aroma/Smell, and Overall }\end{array}$} \\
\hline Appearance & $\begin{array}{l}\text { Extremely } \\
\text { Attractive }\end{array}$ & $\begin{array}{l}\text { Moderately } \\
\text { Attractive }\end{array}$ & $\begin{array}{c}\text { Attractive/ } \\
\text { matches photo }\end{array}$ & Unappetizing & Unattractive \\
\hline Taste/Flavor & Tasted great & Flavorful & Acceptable & Off flavor & $\begin{array}{l}\text { Flavor did not appeal } \\
\text { to me }\end{array}$ \\
\hline Texture Rating & $\begin{array}{l}\text { Wonderful } \\
\text { texture }\end{array}$ & Good texture & $\begin{array}{c}\text { Acceptable } \\
\text { texture }\end{array}$ & Off texture & $\begin{array}{c}\text { Inappropriate } \\
\text { texture/flat/runny }\end{array}$ \\
\hline $\begin{array}{l}\text { Aroma/ Smell } \\
\text { Rating }\end{array}$ & $\begin{array}{c}\text { Wonderful } \\
\text { aroma }\end{array}$ & Appealing aroma & $\begin{array}{c}\text { Acceptable } \\
\text { aroma }\end{array}$ & $\begin{array}{l}\text { Aroma is not } \\
\text { appealing }\end{array}$ & Unappetizing aroma \\
\hline $\begin{array}{c}\text { Overall } \\
\text { Acceptability }\end{array}$ & $\begin{array}{l}\text { Extremely } \\
\text { Acceptable }\end{array}$ & $\begin{array}{l}\text { Moderately } \\
\text { Acceptable }\end{array}$ & Acceptable & $\begin{array}{c}\text { Moderately } \\
\text { Unacceptable }\end{array}$ & Unacceptable \\
\hline \multicolumn{3}{|l|}{ Panelist Code: } & \multicolumn{3}{|l|}{ Date: } \\
\hline
\end{tabular}

V.

\section{CONCLUSION}

In this paper the extraction of herbal mixture for bitter liquors and elixirs manufacturing by maceration compared with the rapid solid-liquid dynamic extraction using the Naviglio Extractor allowed to assess that the RSLDE was faster and allowed a better ethyl alcohol recovery after the extraction, due to brief contact between solid and liquid. The dry residue was lower in the case of the RSLDE extracted herbal mixtures because of the absence of colloidal particles. Kinetic curves obtained were interpolated to derive a mathematical model describing the two extraction processes that fit in the same equation: $\mathrm{C}(\mathrm{t})=\mathrm{S}^{*} \mathrm{e}^{-(\mathrm{k} / \mathrm{t})}$. The difference in the extraction kinetics showed a ratio of about 20:1 between the maceration and the RSLDE process. Lastly the taste of bitter produced by RLSDE was judged better than bitter produced by means of conventional maceration process 


\section{REFERENCES}

[1]. Heinrich M., Barnes J., Gibbons S, Williamson E. Fundamentals of pharmacognosy and phytotherapy, Elsevier Ltd, UK, 2012

[2]. Buglass AJ. (Ed) Liqueurs and their Flavorings, in Handbook of Alcoholic Beverages: Technical, Analytical and Nutritional Aspects, Volume I and II, John Wiley \& Sons Ltd, Chichester, UK.,2010

[3]. Sasidharan S, Chen Y, Saravanan D, Sundram KM, Yoga Latha L. Extraction, isolation and characterization of bioactive compounds from plants extracts. African Journal of Traditional, Complementary and Alternative Medicines,, 8(1), 2011, $1-10$.

[4]. Huang G, Li J, Yan L. Antibacterial effects of some herbal extracts and mechanism. Shizhen Guoyi Guoyao, 22(2), 2011, 425-426.

[5]. Zeng Jian-guo, Tan Man-liang, Peng X, Luo Qi. Standardization and quality control of herbal extracts and products. Traditional Herbal Medicine Research Methods, 2011, 377-427.

[6]. Jaeger S, Beffert, Markus HK, Nadberezny D, Frank B, Scheffler A. Preparation of herbal tea as infusion or by maceration at room temperature using mistletoe tea as an example. Scientia Pharmaceutica, 79(1), 2011, , $145-155$.

[7]. Martins HH, Martins ML, Dias MI, Bernardo F, Evaluation of microbiological quality of medicinal plants used in natural infusions. Int. J. Food Microbiol., 2001, 68, 149-153.

[8]. Gangadhar PA, Vinayak PA, Hanamant BS, Mukul SA. Process for the preparation of elixir of herbal extract. Indian Pat. Appl., 2006, 21pp.

[9]. Naviglio D. Naviglio's principle and presentation of an innovative solid-liquid extraction technology: Extractor Naviglio ${ }^{\circledR}$. Analytical Letters, 36(8), .2003, 1647-1659.

[10]. Naviglio D, Ferrrara L, Montesano D, Mele G, Naviglio B, Tomaselli M, Martini F, Pintonello M., Diana S, Saggiomo S. Application of a new solid-liquid extraction technology for the production of lemon liqueur: Extractor Naviglio. Italian Food \& Beverage Technology, 10(26), 2001, 19-27.

[11]. Nota G, Naviglio D, Romano R, Sabia V, Attanasio G, SpagnaMusso S. Examination of the lemon peel maceration step in the preparation of lemon liquor. Italian Food \& Beverage Technology, 24,2001, 5-9.

[12]. Naviglio D, Franchi GG, Rossi I, Fiore G, Massarelli P, Nencini C, Santini A. Preparation of an elixir from common juniper (Juniperus communis L.) berries: the new Naviglio extractor versus the traditional maceration technique. Food Manufacturing Efficiency, 2(3), 2009, 41-47.

[13]. Naviglio D, Pizzolongo F, Ferrara L, Aragon, A, Santini A. Extraction of pure lycopene from industrial tomato byproducts in water using a new high pressure process. Journal of the Science of Food and Agriculture,88, 2008, 24142420 .

[14]. Cutillo F, D’Abrosca B, Della Greca M, Fiorentino A, Carrelli A. Terpenoids and phenol derivatives from Malva silvestris. Phytochemistry,67,2006, 481-485.

[15]. Zimmerman AJ and Weindorf DC. Heavy Metal and Trace Metal Analysis in Soil by Sequential Extraction: A Review of Procedures, International Journal of Analytical Chemistry, 2010, Article ID 387803, 7 pages.

[16]. Formato A, Gallo M, Ianniello D, Montesano D, Naviglio D. Supercritical fluid extraction of $\alpha$-and $\beta$-acids from hops compared to cyclically pressurized solid-liquid extraction. The Journal of Supercritical Fluids, 84,2013, 113-120.

[17]. Meilgaard M.Civille GV; Carr BT. Sensory Evaluation Techniques, 3rd Edition. CRC Press,Boca Raton, FL, p. $387 ., 1999$ 